\title{
The Mediating Effects of Quality Learning on the Overall Learning Experience and Learning Outcomes of STEM Malaysian Students
}

\author{
S. Chee Choy, Joanne Sau Ching Yim*, and Poh Leong Tan \\ Centre for Educational Psychology and Teaching Strategies, Tunku Abdul Rahman University \\ College, Perak Branch Campus, Kampar, Malaysia
}

\begin{abstract}
This study examines the mediating effects of quality learning on the overall learning experience, and learning outcomes for a sample of 1180 Malaysian STEM students. Data were collected using the Quality Assurance Perception Questionnaire for Students (QAPQ-S), a selfreported questionnaire designed to measure students' perceptions of learning quality in higher education. The contribution of this study is the empirical examination of the main exogenous variables in greater depth using SEM-PLS. The research fills a gap in the literature through its analysis of the mediating role of quality learning. The results show that quality learning is a significant mediator of learning skills, teacher support and curriculum in the achievement of learning outcomes. Quality learning fully mediates learning skills and learning outcomes while partially mediating the other relationships. Limitation and implications for practice are also discussed.
\end{abstract}

Quality learning, learning experience, learning outcomes, mediating effects

\section{Introduction}

In the Malaysian Education Blueprint (2015-2025) for Higher Education (MEBHE) (Ministry of Education Malaysia, 2015), one of the aims for Malaysia is to raise the nation's higher education standards to one that is not only known for good value for money and quality of life but one that is also recognised, referred to, and respected internationally for its academic and research expertise. In order to achieve this aim, the MEBHE states six aspirations for students one which is for mastery and appreciation of Science, Technology, Engineering and Mathematics (STEM) subjects. Further to this, the recently launched MEBHE also articulated the need for holistic and balanced graduates with entrepreneurial minds suggesting that rethinking is necessary in making these shifts a reality and new ideas and models of learning are certainly needed so as to bring these aspirations into reality.

* Corresponding author: yimsc@ taruc.edu.my 
This aim is further articulated by the Malaysian Ministry of Higher Education setting new initiatives as part of its effort to cultivate holistic, entrepreneurial and balanced graduates to be globally competitive and meet the needs of Industry 4.0. Universities are focused on personalised learning outcome, defined as demonstrable and achieved learning that are aligned with a set of goals (Biggs \& Tang, 2011) as well as pursuing technologies and innovations on campus that addresses students' learning needs, in short, quality learning (QL).

Quality in design and delivery of courses will determine the QL of an institution in terms of student performance and evaluation especially if these are based on the needs of students (Langstrand, Cronemyr \& Poksinska, 2015). Although the idea is inherently workable, teachers may not be able to or know how to help students reflect on their learning situations because these teachers are more focused on attaining results that satisfy the standards set by the management and achieving their own key performance indexes (Anderson, 2006). QL is often viewed by universities as a concept of "standards" where the level of conditions must be met for the institution to be accredited by an accreditation agency, hence "benchmarking" established "standards" to other equivalent institutions where needed (Elassy, 2015). Hake (1998) and Handlesman (2004) noted that students using interactive-engagement methods designed to promote conceptual understanding through interactive engagement with peers and teachers resulted in the most improvement in performance of their STEM courses. Studies have also found that a supportive learning environment and perceived self-efficacy can significantly influence students' perceptions of course difficulty in STEM courses (Whalen \& Shelley, 2010) and eventually their success in their chosen programmes. Instructor behaviour that are positive like confirmation, clarity and communicating to students that they are acknowledged as valuable, significantly influences student learning outcomes (Goodboy \& Myers, 2008). Further to this, it was found that teachers' communication style and their availability for students encouraged more engagement when learning (Mottet et al., 2005) and development of positive attitudes (Christophel, 1990).

There have been many studies on STEM students in terms of their engagement and customer orientation, there are few on the mediating effects of QL on learning outcomes, hence this study will address the gap in the research. Studies have shown that the overall learning experience in a university comprising of the learning skills used by students to enhance their learning process (Hattie, Biggs \& Purdie, 1996), delivery of lesson and the support of teachers (Goodboy \& Bolkan, 2009, Samudra et al., 2016), the infrastructure and facilities of a university (Nicholson, 2011; Tagg, 2010), the teaching and assessment procedures of a university (Lizzio, Wilson \& Simons, 2002, Entwistle \& Peterson, 2004), the curriculum of the university (Biggs \& Tang, 2011) and learning outcomes (Biggs \& Tang, 2011) is mediated by the support structure provided by a university to help students with self-management and development, namely the QL in a university (Tagg, 2010, Biggs \& Tang, 2011).

\section{Literature review and research hypotheses}

The conceptual framework for this study will consist of five exogenous variables (Learning Skills, Delivery and Support, Resources, Learning Environment and Curriculum), one endogenous variable (Learning Outcome) which are mediated by QL. A discussion of each variable with definition and relevant supporting literature follows. 


\subsection{Learning outcome and quality learning}

All students have to use regulatory processes to help them achieve learning outcomes and will use specific strategies to achieve specific goals (Girash, 2014). Biggs and Tang (2011) suggested that achievement of learning outcomes are dependent on good teaching which is a function of an institutional-wide infrastructure and policies and procedures that ensures this must be put in place. Research has found that students who were less knowledgeable of course content benefitted from teacher initiated instructional prompts in the form of cognitive and metacognitive strategies like organisation skills, control of cognitive processes at the initial stages of learning (Lee \& Kalyuga, 2014).This gives sufficient evidence to suggest that the type of guidance and support that teachers and the QL provided by a university must take into account students' cognitive characteristics to help them achieve their learning outcomes which are demonstrable and can be mapped and aligned with a set of goals (Biggs \& Tang, 2011). The definition of learning outcome is the achieved learning by students that can be mapped and aligned with a set of goals.

Biggs and Tang (2011) also noted that the learning environment in the form of the infrastructure of an institution and the support that is provided to teachers and students will determine the overall QL. The focus for universities is to personalise learning outcomes as well as meet the needs of students using available technologies and innovations, in short, providing these students with QL ( Kobayashi, 2005; Lee \& Kalyuga, 2014). A supportive learning environment that is enhanced with QL, with appropriate teacher affirmations can significantly influence students' perceptions of course difficulty and eventually graduation rates from their programmes (Whalen \& Shelley, 2010; Bolkan \& Goodboy, 2011). In this study, QL is defined as the support structure for personal attribute development provided to students that will eventually allow them to develop the confidence to make decisions about their own learning that are consistent with the policies and procedures of a university and within an organised learning environment (Biggs \& Tang, 2011)

\subsection{Delivery and support}

Teachers who behave inappropriately in terms of the way they manage the subject area taught, and exhibiting overall rudeness to students can significantly influence learning outcomes and the overall QL (Goodboy \& Bolkan, 2009). According to Duschl and Hamilton (2010) the relationship between students and teachers is an interpersonal one that involves social influence and becomes more enhanced when they use appropriate communication behaviours (Goodboy \& Bolkan, 2009). Kunter et al. (2013) noted that the QL for students increased when teachers were motivated to teach, provided more cognitively activating instructions and teaching support. Hence the following hypothesis:

H1. QL mediates the relationship between Delivery and Support and Learning Outcomes

Delivery and support is defined as the quality of teaching and the learning support provided by teachers to their students in the form of appropriate feedback and task learning strategies (Goodboy \& Bolkan, 2009). 


\subsection{Learning skills}

The results of many studies have shown that students use their learning skills when they are accompanied with appropriate and elaborate feedback which helps correct inappropriate task strategies and misconceptions (Harks et al, 2014). Hattie, Biggs and Purdie (1996) further notes that learning skills must be in the context of students' learning where there is a high degree of learner activity and metacognitive awareness focused on the selfmanagement of learning. The development of learning skills in students involving feedback provided by the teacher on students' performance has been shown to be a powerful influence on student learning (Hattie \& Timperley, 2007). Students with poor learning skills and beliefs are not able to achieve or do well in university settings (Hattie \& Gan, 2011). Such learning skills and beliefs have been found to evolve over time and students given QL, can succeed (Ambrose \& Lovett, 2014) in terms of achieving their learning outcomes. However, the mediating effect of QL on learning skills and learning outcome have received little investigation and hence the hypothesis:

H2. QL mediates the relationship between Learning Skills and Learning Outcomes

\subsection{Resources}

The most important ways of improving teaching is to recognise that teaching is a function of institutional resources (Biggs \& Tang, 2011). Hence, policies and procedures that ensure and encourage good teaching and assessment across a university need to focus on students. Resources in a university must be put in place together with quality management to ensure that students can experience overall QL resulting in achievement of learning outcomes. In this study, resources are the infrastructure and facilities provided by a university in terms of quality of teaching staff, volumes available in the library and quality and type of equipment available to students (Nicholson, 2011) to enrich their overall QL.

H3. QL mediates the relationship between Resources and Learning Outcomes

\subsection{Learning environment}

Learning is interactional and underscore the dynamic quality of learning in which the characteristics of students, the learning environment, the timing and nature of the learning come together to influence what is learned (Duschl \& Hamilton, 2010). In short when students are provided learning environments that support QL, they tend to achieve their learning outcomes. Ennis and Chen (2011) also note that when students learn in an environment that supports the complexities associated with learning, they are more likely to understand that process. Choy, Yim and Tan (2017) found that there was a significant relationship between learning environment of a university which they defined as the overall learning climate will support students' achievement of learning outcomes. The available research suggests the following hypothesis:

H4. QL mediates the relationship between Learning Environment and Learning Outcomes 


\subsection{Curriculum}

According to Tyler (2013), a well-designed curriculum must contain educational goals to be achieved and learning experiences which are well organised as well as attainable learning outcomes. Learning experiences are the interactions of students with external conditions, that is QL, in the learning environment to which they can react. Doll (1993) notes that a curriculum that allows for student transformation, encourages the development of their natural capacity for complex organisation, hence the teachers' role is transformative and not causal, focusing on the process of learning. In this study, curriculum is defined as the arrangement and structure of courses that are for a specified duration to achieve stated learning outcomes and provides a 'map' to indicate what students can do after teaching (Biggs \& Tang 2011). The available research suggested the following hypothesis:

\section{$\mathrm{H}_{5}$ : QL mediates the relationship between Curriculum and Learning Outcomes}

The conceptual framework of the mediating effects of QL on students' perspective of learning consisting of five exogenous variables and the endogenous variable, learning outcome is shown in Figure 1.

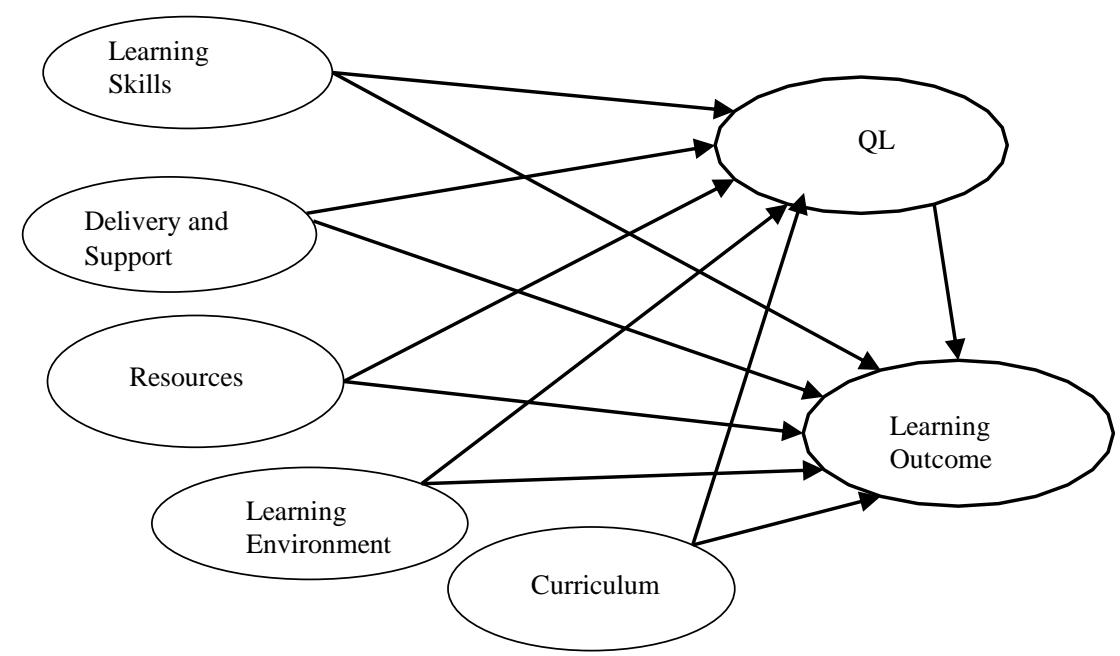

Fig. 1. Conceptual Framework of the Mediating Effects of QL on Student Perspective of Learning and Learning Outcomes

\section{Method}

\subsection{Sampling and data collection}

A total of 1043 students consisting of 739 males and 304 females with a mean age of 20 $(\mathrm{SD}=1.361)$ enrolled in bachelor and diploma programmes at a university in Malaysia participated in this study. The samples were from one faculty in the University. The participants were assured their anonymity and confidentiality of information provided. They were also informed of the nature of the study and were told they could withdraw from the study anytime during or after the study. 


\subsection{Measurement scales}

The study's main constructs were measured using items adapted from of the Quality Assurance Perception Questionnaire - Student (QAPQ-S) (Choy, Yim \& Tan 2017), a questionnaire designed to measure the following areas: learning outcomes, curriculum design and delivery; student support, learning environment, academic staff, educational resources, and learning quality.

\subsection{Limitation of the study}

It must be noted that the data were collected from the social science faculty of only one university in Malaysia. Although the sample collected provided an acceptable quality in terms of outer loadings of 0.70 (Hair et al, 2017), it is still a self-reported instrument and hence the truthfulness of the respondents cannot be assured.

\subsection{Data analysis}

The present study employed the non-parametric Partial Least Squares (PLS) SEM approach to analyse data because the study is exploratory in nature. The model specified in this study has seven constructs with reflective measurements and the path model was estimated using SMART-PLS 3.0. Table 1 shows the internal consistency of constructs and variance inflated factor (VIF). The composite reliability for each construct was above 7.0 and showed satisfactory levels of internal consistency reliability. The AVE for all the constructs were between 0.567 and 0.782 satisfying the requirement for convergent reliability (Hair, et al., 2017). The VIF for the constructs are less than 3.3 (Diamantopoulos, \& Siguaw, 2006) hence collinearity is not an issue. 
Table 1. Internal Consistency of Constructs and Variance Inflator Factor (VIF)

\begin{tabular}{|c|c|c|c|c|c|c|}
\hline \multirow[t]{2}{*}{ Constructs } & \multirow[t]{2}{*}{ Items } & \multirow{2}{*}{$\begin{array}{c}\text { Item } \\
\text { loading }\end{array}$} & \multirow{2}{*}{$\begin{array}{l}\text { Composite } \\
\text { Reliability }\end{array}$} & \multirow[t]{2}{*}{$\overline{A V E}$} & \multicolumn{2}{|c|}{ VIF } \\
\hline & & & & & $\begin{array}{l}\text { Learning } \\
\text { Outcome }\end{array}$ & $\begin{array}{c}\text { Quality } \\
\text { Learning }\end{array}$ \\
\hline \multirow[t]{3}{*}{ Curriculum } & CU1 & 0.814 & \multirow[t]{3}{*}{0.815} & \multirow[t]{3}{*}{0.596} & \multirow[t]{3}{*}{1.629} & \multirow[t]{3}{*}{1.552} \\
\hline & CU2 & 0.762 & & & & \\
\hline & CU3 & 0.738 & & & & \\
\hline \multirow{2}{*}{$\begin{array}{l}\text { Delivery \& } \\
\text { Support }\end{array}$} & DS1 & 0.874 & \multirow[t]{2}{*}{0.878} & \multirow[t]{2}{*}{0.782} & \multirow[t]{2}{*}{1.59} & \multirow[t]{2}{*}{1.461} \\
\hline & DS2 & 0.895 & & & & \\
\hline \multirow{3}{*}{$\begin{array}{l}\text { Learning } \\
\text { Environment }\end{array}$} & LE1 & 0.794 & \multirow[t]{3}{*}{0.832} & \multirow[t]{3}{*}{0.623} & \multirow[t]{3}{*}{1.696} & \multirow[t]{3}{*}{1.662} \\
\hline & LE2 & 0.833 & & & & \\
\hline & LE3 & 0.738 & & & & \\
\hline \multirow{4}{*}{$\begin{array}{l}\text { Learning } \\
\text { Outcomes }\end{array}$} & LO1 & 0.804 & \multirow[t]{4}{*}{0.869} & \multirow[t]{4}{*}{0.624} & \multirow[t]{4}{*}{ N/A } & \multirow[t]{4}{*}{ N/A } \\
\hline & LO2 & 0.808 & & & & \\
\hline & LO3 & 0.793 & & & & \\
\hline & $\mathrm{LO} 4$ & 0.754 & & & & \\
\hline \multirow{3}{*}{$\begin{array}{l}\text { Learning } \\
\text { Skill }\end{array}$} & LS1 & 0.733 & \multirow[t]{3}{*}{0.797} & \multirow[t]{3}{*}{0.567} & \multirow[t]{3}{*}{1.678} & \multirow[t]{3}{*}{1.641} \\
\hline & LS2 & 0.735 & & & & \\
\hline & LS3 & 0.789 & & & & \\
\hline \multirow{2}{*}{$\begin{array}{l}\text { Quality } \\
\text { Learning }\end{array}$} & QL1 & 0.824 & \multirow[t]{2}{*}{0.806} & \multirow[t]{2}{*}{0.675} & 1.714 & N/A \\
\hline & QL2 & 0.820 & & & & \\
\hline Resources & $\mathrm{R} 1$ & 0.767 & 0.854 & 0.594 & 1.34 & 1.328 \\
\hline & $\mathrm{R} 2$ & 0.774 & & & & \\
\hline & R3 & 0.729 & & & & \\
\hline & R4 & 0.810 & & & & \\
\hline
\end{tabular}

In establishing discriminant validity, Table 2 shows the Fornell-Larcker criterion where the square-roots of AVE for all constructs were greater its correlations with other constructs (Fornell \& Larcker, 1981). The square roots of the AVE are in the diagonal. In addition, Table 3 shows the heterotrait-monotrait (HTMT) criterion which imposes a more stringent assessment suggests that all constructs are distinctly different at $\mathrm{HTMT}_{0.90}$ threshold (Hensler, Ringle \& Sartstedt, 2015). 
Table 2. Discriminant Validity - Fornell and Larcker criterion

\begin{tabular}{|l|l|l|l|l|l|l|l|}
\hline & C & DS & LE & LO & LS & QL & R \\
\hline C & $(0.772)$ & & & & & & \\
\hline DS & 0.411 & $(0.885)$ & & & & & \\
\hline LE & 0.513 & 0.47 & $(0.789)$ & & & & \\
\hline LO & 0.520 & 0.462 & 0.606 & $(0.790)$ & & & \\
\hline LS & 0.483 & 0.475 & 0.487 & 0.461 & $(0.753)$ & & \\
\hline QL & 0.497 & 0.522 & 0.482 & 0.529 & 0.482 & $(0.822)$ & \\
\hline R & 0.365 & 0.318 & 0.408 & 0.392 & 0.425 & 0.365 & $(0.771)$ \\
\hline
\end{tabular}

Note $: \mathrm{C}=$ Curriculum; DS = Delivery \& Support; LS = Learning Skill; LE = Learning Environment; $\mathrm{LO}=$ Learning Outcomes; $\mathrm{R}=$ Resources; $\mathrm{QL}=$ Quality Learning

Table 3. Discriminant Validity - HTMT Criterion

\begin{tabular}{|l|l|l|l|l|l|l|l|}
\hline & C & DS & LE & LO & LS & QL & R \\
\hline C & & & & & & & \\
\hline DS & 0.593 & & & & & & \\
\hline LE & 0.751 & 0.659 & & & & & \\
\hline LO & 0.717 & 0.608 & 0.807 & & & & \\
\hline LS & 0.723 & 0.629 & 0.679 & 0.604 & & & \\
\hline QL & 0.849 & 0.851 & 0.798 & 0.82 & 0.764 & & \\
\hline R & 0.502 & 0.417 & 0.547 & 0.492 & 0.585 & 0.564 & \\
\hline
\end{tabular}

Note : C = Curriculum; DS = Delivery \& Support; LS = Learning Skill; LE = Learning Environment; $\mathrm{LO}=$ Learning Outcomes; $\mathrm{R}=$ Resources; $\mathrm{QL}=$ Quality Learning

Table 4. Mediation Analysis

\begin{tabular}{|c|c|c|c|c|c|c|c|}
\hline \multicolumn{2}{|c|}{$\begin{array}{l}\text { Predictor } \rightarrow>\text { Mediator }-> \\
\text { Criterion }\end{array}$} & \multicolumn{2}{|l|}{ Effects } & \multirow{2}{*}{$\begin{array}{l}\begin{array}{l}\text { Standard } \\
\text { Deviation } \\
\text { (STDEV) }\end{array} \\
0.035\end{array}$} & \multirow{2}{*}{$\begin{array}{l}\text {-value } \\
2.584^{* *}\end{array}$} & \multirow{2}{*}{$\begin{array}{l}p \text { - } \\
\text { values } \\
0.010\end{array}$} & \multirow{3}{*}{$\begin{array}{l}\text { Mediation type } \\
\text { Complementary } \\
\text { partial } \\
\text { mediation }\end{array}$} \\
\hline \multirow[t]{2}{*}{$\mathrm{H} 1$} & \multirow[t]{2}{*}{ DS $>$ QL $>$ LO } & Direct & 0.091 & & & & \\
\hline & & Indirect & 0.05 & 0.013 & $3.860 * *$ & 0.000 & \\
\hline \multirow[t]{2}{*}{$\mathrm{H} 2$} & \multirow[t]{2}{*}{ LS -> QL $->$ LO } & Direct & 0.054 & 0.034 & 1.605 & 0.109 & \multirow{2}{*}{$\begin{array}{l}\text { Indirect only } \\
\text { Full mediation }\end{array}$} \\
\hline & & Indirect & 0.027 & 0.009 & $3.089 * *$ & 0.002 & \\
\hline \multirow[t]{2}{*}{ H3 } & \multirow[t]{2}{*}{ R -> QL -> LO } & Dire & 0.077 & 0.031 & $2.492 * *$ & 0.013 & \multirow{2}{*}{$\begin{array}{l}\text { Complementary } \\
\text { partial } \\
\text { mediation }\end{array}$} \\
\hline & & Indirect & 0.015 & 0.006 & $2.413^{* *}$ & 0.016 & \\
\hline \multirow[t]{2}{*}{$\mathrm{H} 4$} & \multirow[t]{2}{*}{ LE $>$ QL $>>$ LO } & Dire & 0.331 & 0.037 & $9.051 * *$ & 0.000 & \multirow{2}{*}{$\begin{array}{l}\text { Complementary } \\
\text { partial } \\
\text { mediation }\end{array}$} \\
\hline & & Indirect & 0.026 & 0.009 & $2.957 * *$ & 0.003 & \\
\hline \multirow[t]{2}{*}{ H5 } & \multirow[t]{2}{*}{ C $\rightarrow$ QL $->$ LO } & Direct & 0.167 & 0.033 & $5.099 * *$ & 0.000 & \multirow{2}{*}{$\begin{array}{l}\text { Complementary } \\
\text { partial } \\
\text { mediation }\end{array}$} \\
\hline & & Indirect & 0.039 & 0.010 & $3.837 * *$ & 0.000 & \\
\hline
\end{tabular}

Note: $* *$ t-value $>1.96$, (two-tailed)

$\mathrm{C}=$ Curriculum; DS = Delivery \& Support; LS = Learning Skill; LE = Learning Environment; LO = Learning Outcomes; $\mathrm{R}=$ Resources; $\mathrm{QL}=$ Quality Learning 
The structural model for this study involved seven constructs at two levels of relationships. The five predictor variables are Learning Skills, Delivery and Support, Resources, Learning Environment, and Curriculum. Learning Quality mediates the between the five predictor variable and the final target construct Learning Outcomes. The bootstrapping results (Table 4) for testing the mediation effects (Preacher \& Hayes, 2004) of Learning Quality between Delivery and Support, Learning Skills, Resources, Learning Environment and Curriculum and Learning Outcomes at 95\% confidence interval confirmed the mediator role of Learning Quality. Based on the interpretation of "complementary mediation" (Zhao et al., 2010), QL has a complementary mediating effect on the relationship between Learning Outcomes, and Delivery and Support (H1), Resources (H3), Learning Environment (H4), and Curriculum (H5), demonstrating partial mediation for these relationships. This is evident from the indirect and direct effects which are all significant and point in the same direction. It was also found that QL fully mediates the relationship between Learning Skills and Learning Outcomes (H2), implying that QL accounts for all of the observed relationship between the two variables. This is demonstrated by the insignificant direct effect and significant indirect effect obtained for this relationship.

\subsection{Discussion}

The study examined the role of QL in STEM students' achievement of their learning outcomes in a Malaysian university. In this study, Hypothesis 1 was supported, QL partially mediates between delivery and support and learning outcomes. Hypothesis 2 was supported, QL fully mediates the relationship between learning skills and learning outcomes. Hypothesis 3 was supported, QL partially mediates the relationship between resources and learning outcomes. Hypothesis 4 was supported, QL partially mediates the relationship between learning environment and learning outcomes. Hypothesis 5 was supported, QL partially mediates the relationship between curriculum and learning outcomes.

In this study, QL is defined as the structure and process that is provided to help students develop confidence and decision-making skills. QL is the support structure for personal attribute development that will allow them to make decision about their own learning, Evidence from this study showed that learning skills, defined as the strategies and tactics used by students to manage themselves (Hattie at al., 1996), was found to be fully influenced by QL, suggesting the structure provided to students which addresses personal development attributes will influence the overall achievement of learning outcomes. Hence, STEM students who are given challenging but achievable learning goals, experiences improved learning especially if they are allowed and trusted to make decisions and take responsibilities for their own learning in an environment that is organised and supportive of their learning experience (Biggs \& Tang, 2011).

Another two factors partially influenced by QL is delivery and support, the support provided to students by their teachers and curriculum, the structured arrangement of courses. The finding in this study suggests that the structure and support provided by a university in the form of its curriculum can, together with the support given by teachers to their students in this case STEM students, influence the achievement of learning outcomes. Hence the design and delivery of courses is influenced by QL and care needs to be taken that it is tailored to the needs of students (Langstrad et al., 2015) and should not be viewed by universities as a means of achieving required standards (Elassy, 2015). A well organised and fully explained lesson helps students sustain their attention, leading to better understanding and subsequently more learning (Samudra et al., 2016). 
Curriculum defined as the 'map' of what students can do after a stipulated period of learning, was also partially influenced by QL in the achievement of learning outcomes. It is possible that students perceive a supportive teaching environment with appropriate teacher affirmation can significantly mitigate course difficulty (Bolkan \& Goodboy, 2011), and together with a well-structured curriculum can help them achieve their learning outcomes.

The results showed that QL also partially mediated the relationship between resources and learning environment, defined as the facilities and infrastructure of a university and the quality of the academic staff and procedures of a university respectively. These physical factors remain important even with the increased use of educational technologies such as web-based learning environments, augmented reality, digital games, and gamifications of lessons to improve STEM learning outcomes. Further research is needed to include educational technologies as part of the resources and learning environment, to examine their influence of STEM students' perception of QL.

QL fully mediated learning skills and partially mediated delivery and support and curriculum to influence the achievement of learning outcomes. The other two factors did not show significant mediation levels by QL. When applied to the Malaysian context, the findings imply the importance placed by STEM students on the support structure provided by a university in terms of the structure of their courses and how they are taught and delivered and the guidance given to help in the personal development of students.

\section{Conclusion and implications for practice}

The results of this study showed that QL fully mediates the relationship between learning skills and learning outcomes and partially mediated the relationship between delivery and support, curriculum, learning environment, resources and learning outcomes. Although universities aspire for students to develop mastery of their own disciplines as well as apply and connect all knowledge in order to possess marketable job skills to meet the needs of Industry 4.0, the results of this study indicate students are more focused on having institutions meet their individual needs in terms of self-development with their teachers providing the necessary guidance. This is supported by results indicating students' association of acquiring learning skills to the type of QL provided by the university. Although outcomes based learning has been the emphasis and has been implemented with relative success in many Malaysian universities, students may continue to be teacher centred in their views of learning. Hence students may tend to view QL more in terms of their teachers and the structure of their programme rather than the university environment and experience as a whole. These findings hint at the remnants of an examination oriented system where the teacher is notably seen as an authority of knowledge rather than as a facilitator of learning. Such perceptions will take time to change and the aims for Malaysian students to be critical thinkers continue to be a difficult but ultimately an attainable goal. These results have clear implications for university teachers and administrators alike. There must be more effort in place to help students experience holistic learning to mould and develop them to be graduates with the necessary skills that meet market demands for employability.

\section{References}

Ambrose, S., \& Lovett, M. (2014). Prior knowledge is more than content: Skills and beliefs also impact learning. In V. Benassi, C. Overson, \& C. Hakala, Applying Science of learning in education: Infusing psychological science into the curriculum (pp. 7-19). Retrieved from 
the Society for the Teaching of Psychology web site: http://teachpsych.org/ebooks/asle2014/index.php.

Anderson, G. (2006). Assuring Quality/ Resisting Quality Assurance: Academics' responses to 'quality' in some Australian universities. Quality in Higher Education, 12(2), 161-173. http://dx.doi.org/10.1080/13538320600916767.

Biggs, J., \& Tang, C. (2011). Teaching for quality learning at University: What the student does. Berkshire: McGraw Hill.

Bolkan, S., \& Goodboy, A. (2011). Behavioural indicators of teansformational leadership in the college classroom. Qualitative Research Reports in Communication, 12(1), 10-18. DOI: 10.1080/17459435.2011.601520.

Choy, S. C., Yim, J. S., \& Tan, P. L. (2017). Students' and teachers' perceptions of learning quality and learning outcomes in a Malaysian university. Journal of Institutional Research in South East Asia, 15(1), 41-62.

Choy, S. C., Yim, S., \& Tan, P. L. (2017). Students' perceptions of quality learning in a Malaysian university - A mixed method approach. Quality Assurance in education, https://doi.org/10.1108/QAE-12-2016-0088.

Christophel, D. (1990). The relationships among teacher immediacy behaviors, student motivation, and learning. Communication Education, 39:4, 323-340, DOI:10.1080/03634529009378813.

Diamantopoulos, A., \& Siguaw, J. A. (2006). Formative versus reflective indicators in organizational measure development: A comparison and empirical illustration. British Journal of Management, 17, 263-282 ,DOI: 10.1111/j.1467-8551.2006.00500.x.

Doll, W. E. (1993). A post-modern perspective on curriculum. New York: Teachers College Press.

Duschl, R., \& Hamilton, R. (2010). Learning science. In R. E. Mayer, \& P. A. Alexander, Handbook of research on learning and instruction (pp. 78-107). London: Routlege.

Elassy, N. (2015). The concepts of quality, quality assurance and quality enhancement. Quality Assurance in Education, 23 (3), 250-261. http://dx.doi.org/10.1108/QAE-11-20120046.

Ennis, C., \& Chen, A. (2011). Learning motor skill in physical education. In R. Mayer, \& P. Alexander, Handbook of research on learning and instruction (pp. 148-165). London : Routledge.

Entwistle, N. J., \& Peterson, E. R. (2004). Conceptions of learning and knowledge in higher education: Relationships with study behaviourand influences of learning environments. International Journal of Education Research, 41, 407-428. 
Fornell, C., \& Larcker, D. F. (1981). Evaluating structural equation models with unobservable variables and measurement error. journal of marketing research, 48, 39-50.

Girash, J. (2014). Metacognition and instruction. In V. A. Benassi, C. E. Overson, \& C. M. Hakala, Applying science of learning in education: Infusing psychological science into the curriculum. (pp. 152-168). Retrieved from the Society for the Teaching of Psychology web site: http://teachpsych.org/ebooks/asle2014/index.php.

Goodboy, A., \& Myers, S. (2008). The effect of teacher confirmation on student communication and learning outcomes. Communication Education, 57(2), 153-179. DOI: $10.1080 / 03634520701787777$.

Goodboy, K., \& Bolkan, S. (2009). College teacher misbehaviors: Direct and indirect effects on student communication behavior and traditional learning outcomes. Journal of Communication, 73:2, 204-219, DOI: 10.1080/10570310902856089.

Hair, J. F., Hult, G. T., Ringle, C. M., \& Sarstedt, M. (2017). A primer on partial least squares structural equation modelling (PLS-SEM). Los Angeles: Sage.

Hake, R. (1998). Interactive-engagement versus traditional methods: A six-thousandstudent survey of mechanics test data for introductory physics courses. American Journal of Physics, 66, 64-74. doi: http://dx.doi.org/10.1119/1.18809.

Handelsman, J., Ebert-May, D., Beichner, R., Bruns, P., Chang, A., DeHaan, R., et al. (2004). Scientific teaching. Science, 304, 521-522. DOI: 10.1126/science.1096022.

Harks, B., Rakoczy, K., Hattie, J., Besser, m., \& Klieme, E. (2014). The effects of feedback on achievement, interest and self-evaluation: the role of feedback's perceived usefulness. Educational Psychology, 34:3, 269-290. DOI: 10.1080/01443410.2013.785384.

Hattie, J., \& Gan, M. (2011). Instruction based on feedback. In R. E. Mayer, \& P. A. Alexander, Handbook of Research on Learning and Instruction (pp. 249-271). London: Taylor \& Francis.

Hattie, J., \& Timperley, H. (2007). The power of feedback. Review of Educational Research, Vol. 77, No. 1 (Mar., 2007), pp. 81-112, 77(1), 81-112.

Hattie, J., Biggs, J., \& Purdie, N. (1996). Effects of learning skills interventions on student learning: A meta-analysis. Review of Educational Research, 66(2 ), 99- 136. DOI: $10.3102 / 00346543066002099$.

Hensler, J., Ringle, C., \& Sarstedt, M. (2015). A new criterion for assessing discriminant validity in variance-based structural equation modelling. Journal of the Academy of Marketing Science, 43(1),115-135.

Kobayashi, K. (2005). What limits the encoding effect of note-taking?: A meta-analytic examination. Contemporary Educational Psychology, 30, 242-262.

doi:10.1016/j.cedpsych.2004.10.001. 
Kunter, M., Klusmann, U., Baumert, J., Richter, D., Voss, T., \& Hachfeld, A. (2013). Professional competence of teachers: Effects on instructional quality and student development. Journal of Educational Psychology, 105 (3), 805-820. DOI: 10.1037/a0032583.

Langstrand, J., Cronemyr, P., \& Poksinska, B. (2015). Practise what you preach: quality of education in education on quality. Total Quality Management \& Business Excellence, 26 (11-12) , 1202-1212, DOI: 10.1080/14783363.2014.925290.

Lee, C. H., \& Kalyuga, S. (2014). Expertise reversal effect and its instructional implications. In V. Benassi, C. Overson, \& C. Hakala, Applying science of learning in education: Infusing psychological science into the curriculum (pp. 31-44). Retrieved from the Society for the Teaching of Psychology web site: http://teachpsych.org/ebooks/asle2014/index.php.

Lizzio, A., Wilson, K., \& Simons, R. (2002). University students' perceptions of the learning environment and academic outcomes: Implications for theory and practice. Studies in Higher Education , 27(1), 27-52.

Ministry of Education Malaysia. (2015). Malaysia Education Blueprint 2015-2025 (Higher Education). Putrajaya: Ministry of Education Malaysia.

Mottet, T., Parker-Raley, J., Cunningham, C., \& Beebe, S. (2005). The relationships between teacher nonverbal immediacy and student course workload and teacher availability expectations. Communication Research Reports, 22(4), 275-282. DOI:

10.1080/000368105000317482.

Nicholson, K. (2011). Quality assurance in higher education: A review of the literature. Ontario: Council of Ontario Universities Degree Level Expectations Project, McMaster University.

Preacher, K. J., \& Hayes, A. F. (2004). SPSS and SAS procedures for estimating indirect effects in simple mediation models. Behaviour Research methods, 36(4) 717-731.

Samudra, P. G., Kai, I. M., Cortina, S., \& Miller, K. F. (2016). No second chance to make a first impression: The "thin-slice" effect on instructor ratings and learning outcomes in higher education. Journal of Educational Measurement, 53(3), 313-331. DOI: $10.1111 /$ jedm. 12116 .

Tagg, J. (2010). The learning-paradigm campus: From single- to double-loop learning . New Directions for teaching and Learning , 123, 51-61. DOI:10.1002/tl.409. Tyler, R. (2013). Basic prinicples of curriculum and instruction. Chicago: The University of Chicago Press.

Whalen, D., \& Shelley, M. (2010). Academic success for STEM and non-STEM majors. Journal of STEM Education, 11(1), 46-60.

Zhao, X., Lynch, J. G., \& Chen, Q. (2010). Baron and Kenny: Myths and Truths about Mediation Analysis. Journal of Consumer Research, 37,(2), 197-206. 